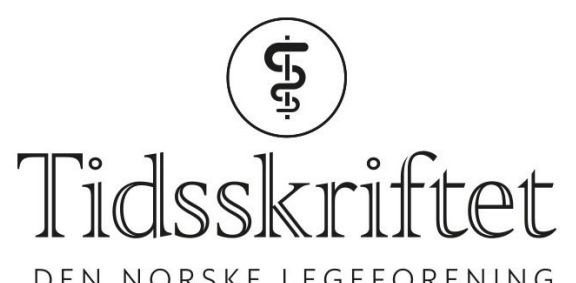

DEN NORSKE LEGEFORENING

\title{
Desentraliserte helsetjenester
}

KRONIKK

\section{ANN-CHATRIN LINQVIST LEONARDSEN}

E-post: dleo@online.no

Ann-Chatrin Linqvist Leonardsen (f.1974) er anestesisykepleier og ph.d. i helsetjenesteforskning. Doktorgradsavhandlingen omhandlet kommunale akutte døgnenheter. Hun er forsker/postdoktor ved Sykehuset Østfold.

Forfatter har fylt ut ICMJE-skjemaet og oppgir ingen interessekonflikter.

\section{ØYSTEIN LAPPEGARD}

Øystein Lappegard (f. 1952) er dr.med., ph.d., spesialist i samfunnsmedisin og kommuneoverlege i Ål kommune. Doktorgradsavhandlingen omhandlet Hallingdal sjukestugu. Forfatter har fylt ut ICMJE-skjemaet og oppgir ingen interessekonflikter.

\section{HELGE GARÅSEN}

Helge Garåsen (f. 1952) er dr.med., ph.d., spesialist i samfunnsmedisin, kommunaldirektør i Trondheim kommune og førsteamanuensis II ved Norges teknisk-naturvitenskapelige universitet. Doktorgradsavhandlingen omhandlet intermediærbehandling i sykehjem i Trondheim. Forfatter har fylt ut ICMJE-skjemaet og oppgir ingen interessekonflikter.

\section{IVAR JOHANNES AARAAS}

Ivar Johannes Aaraas (f. 1944) er pensjonert professor ved Institutt for samfunnsmedisin og Nasjonalt senter for distriktsmedisin, Universitetet i Troms $\emptyset$ - Norges arktiske universitet, nå seniorrådgiver/veileder. Doktorgradsavhandlingen omhandlet sykestuene i Finnmark. Forfatter har fylt ut ICMJE-skjemaet og oppgir ingen interessekonflikter.

De siste årene har det i norsk helsevesen vært et mål å overføre tjenester fra spesialist- til primærhelsetjenesten. I skjæringspunktet mellom de to forvaltningsnivåene har det vokst frem en rekke ulike løsninger. Hva vet vi om disse løsningene, og hvordan kan vi skape en bedre helsetjeneste i denne gråsonen mellom kommuner og sykehus? 


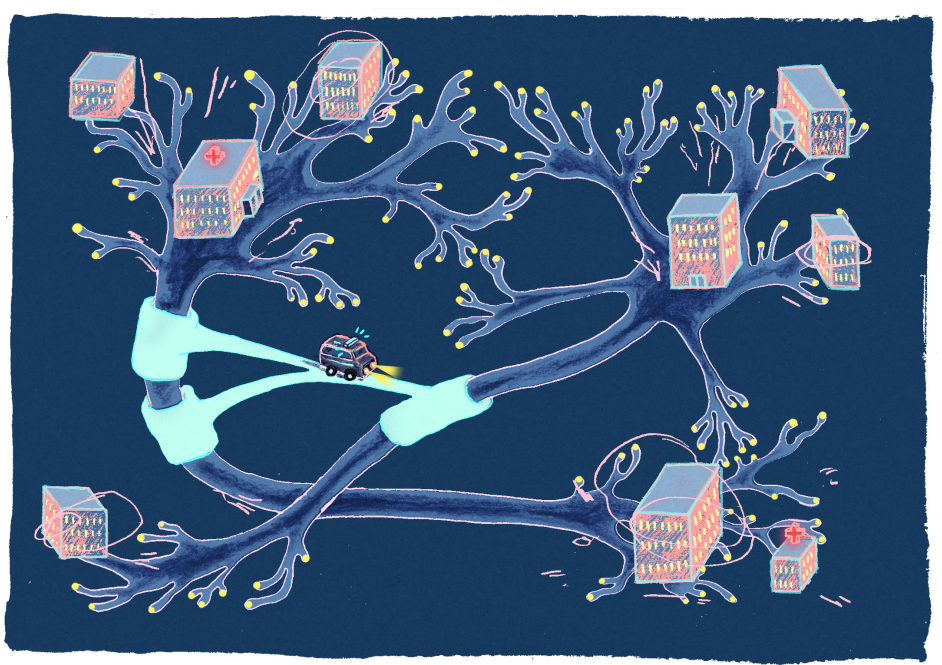

Illustrasjon: Sylvia Stølan

Helsevesenet i Norge har utviklet seg i spenningen mellom desentralisering og sentralisering (1). De siste årene har fokus vært på desentralisering av tjenester fra spesialisthelsetjenesten til kommunene, effektivisering og bedre koordinering av tjenestene (2). Nåværende helse- og omsorgsminister har lansert begrepet "pasientens helsetjeneste”, der bedre forståelse for pasientenes verdier og preferanser er avgjørende for å tilby helsetjenester av god kvalitet.

Implementeringen av samhandlingsreformen og "rett behandling på rett sted til rett tid", har ført til en videre opprusting av helsetjenestene i kommunene (3). Kommunale akutte døgnenheter ble introdusert som kommunale, døgnkontinuerlige tilbud om akutte helsetjenester til pasienter som trenger medisinsk behandling og omsorg, men som ikke trenger innleggelse i sykehus. Det primære innleggelseskriteriet er at pasienten ellers ville blitt innlagt på sykehus. Regjeringen har satt som krav at dette tilbudet skal ha samme eller bedre kvalitet som i sykehusene. Det ser ut til at opprettelsen av kommunale akutte døgnenheter har ført til en reduksjon i antall sykehusinnleggelser. Særlig er det dokumentasjon for dette for pasienter over 80 år, når lege er tilgjengelig døgnet rundt, og der hvor enheten er samlokalisert med legevakt (4).

Denne artikkelen vil presentere funn fra artikkelforfatternes doktorgradsavhandlinger som har sett på desentraliserte helsetjenester ved sykestuer, intermediæravdelinger og kommunale akutte døgnenheter. Vi ønsker å belyse at slike lokale behandlingstilbud kan være formålstjenlig både fra et samfunns- og et pasientperspektiv og ikke bør avgrenses til kun å være et alternativ til sykehusinnleggelse.

\section{Sykestuene i Finnmark}

I en eldre artikkelserie i Tidsskriftet belyste Andreas B. Wessel (1858-1940) den historiske utviklingen av sykestuer i perioden 1850-1929 med hovedvekt på sykestuene i Finnmark (5). Disse ble brent under den annen verdenskrig, men senere gjenoppbygd. Etter krigen ble det bygd opp sykestuer over hele landet. I 1972 var det 64 sykestuer med vel 1 ooo senger spredt over 15 fylker. Sykestuene ivaretok mye av det samme tilbudet man i dag tilstreber ved oppbygging av intermediæravdelinger og kommunale akutte døgnenheter. Ved sykehusutbyggingen i 1970-årene ble sykestuene nedbygd. I 1994 var det kun 171 senger igjen, de fleste i Finnmark. Basert på data fra sykestuer og sykehus i Finnmark gjennomførte Aaraas sitt doktorgradsarbeid i 1990-årene (6). Prospektive og retrospektive registreringer av 395 sykestueopphold, 2496 pasient-lege-kontakter og 35435 sykehusopphold, viste at alvorlig syke pasienter som ble overført videre til sykehus i hovedsak ikke hadde helsetap ved primær innleggelse på sykestue. Akutt behandling på sykestue før videre transport til sykehus, bidro til å hindre varig helsetap/død for enkelte pasienter. Sykestueoppholdene erstattet innleggelser i sykehus, først og fremst som korttidsopphold og observasjon av utvalgte medisinske problemstillinger. Sykestuetilbudet medførte også lavere kostnader for 
samfunnet enn alternative tilbud.

\section{Intermediæravdelinger}

Intermediæravdelinger er enheter med lavere bemanning og mindre medisinskteknologisk utstyr enn ordinære sykehus. Målgruppen er eldre pasienter som ellers ville ha fått uhensiktsmessige innleggelser eller unødvendig forlenget opphold ved sykehus, og målsetningen er økt selvstendighet og evne til å greie seg i eget hjem. Behandlingstiden er som regel tidsavgrenset innenfor 1-2 uker (7).

Et eksempel på et intermediært tilbud fra Norge er Søbstad helsehus hvor enkelte sengeplasser i 2002 ble omorganisert til en intermediærenhet. Enheten kunne tilby behandling, omsorg og rehabilitering til pasienter over 6o år som var blitt undersøkt, og behandlingen initiert på sykehus. Dette var altså ikke et alternativ til sykehusinnleggelse, men en etterbehandling. Pasienter med alvorlig demens eller psykisk sykdom ble ekskludert. Garåsen gjennomførte en randomisert kontrollert studie ved denne enheten som del av sitt doktorgradsarbeid i 2008 (8). I studien sammenlignet man flere utfallsmål blant 72 pasienter over 60 år som ble utskrevet fra sykehus direkte til hjemmet, og 70 pasienter over 60 år som ble utskrevet fra sykehus, via intermediæravdelingen, til hjemmet. Sluttbehandling på intermediært nivå i sykehjem medførte færre reinnleggelser, større egenomsorgsevne etter hjemkomst og lavere dødelighet etter seks og tolv måneders oppfølging. Intermediæravdelingen ble også vist å være kostnadseffektiv, først og fremst på grunn av reduserte kostnader i sykehuset (8). Det er i Norge blitt etablert flere helsehus etter modell fra Søbstad som for eksempel Øya helsehus i Trondheim, i Lillehammer og i Oslo.

\section{Hallingdal sjukestugu}

Hallingdal sjukestugu har vært drevet av spesialisthelsetjenesten i over zo år, og fra 1995 som en avdeling tilknyttet Ringerike sykehus, som ligger 15 mil unna. Sykestuen består blant annet av en somatisk døgnavdeling, en somatisk poliklinikk med ambulerende spesialister og røntgentilbud med digital overføring til sykehuset. Den somatiske døgnavdelingen gir tilbud både før, i stedet for og etter sykehusbehandling. Lappegard belyste i sitt doktorgradsarbeid helsekonsekvenser, opplevd kvalitet og økonomi ved akuttinnleggelser ved henholdsvis Hallingdal sjukestugu $(\mathrm{n}=33)$ og Ringerike sykehus $(\mathrm{n}=$ 27) (9). Studien besto av både registerdata, en randomisert kontrollert studie, spørreskjemaundersøkelse og intervjuer med pasienter innlagt ved de to ulike tilbudene. Det var ingen statistisk signifikant forskjell i grad av funksjonsnivå, mortalitet eller reinnleggelser for de to gruppene. Desentralisert innleggelse viste likevel en tendens mot et lavere forbruk av helsetjenester etter utskrivning. Videre fant man at pasientopplevd kvalitet ved sykestuen var signifikant bedre enn ved sykehuset. Pasientene rapporterte positivt om en hjemlig atmosfære, oversiktlige forhold, nærhet til lokalsamfunnet og kontinuitet i forholdet mellom pasient og behandler. Det var også signifikant lavere kostnad ved akuttinnleggelser på Hallingdal sjukestugu.

\section{Kommunale akutte døgnenheter}

Kommunale akutte døgnenheter ble i tråd med samhandlingsreformen lovpålagt som et kommunalt tilbud fra 1. januar 2016. Slike enheter etableres over hele landet som alternative behandlingstilbud for pasienter som trenger medisinsk behandling og omsorg, men som ikke trenger sykehusinnleggelse. Leonardsen undersøkte i sitt doktorgradsarbeid fra 2017 erfaringer med fem slike enheter i Østfold (10). Det ble benyttet spørreskjema til pasienter utskrevet fra kommunal akutt døgnenhet $(n=479)$, i tillegg til semistrukturert intervju med 27 pasienter og med 23 fastleger. Studien viste at fastlegene var usikre på om oppfølgingen ved de desentraliserte enhetene var tilstrekkelig og trygg ut fra diagnostiske begrensninger. Pasienter rapporterte at behandlingen sett med deres øyne, var 
sammenlignbar med sykehusbehandling, men at de opplevde begrensninger relatert til diagnostiske muligheter. Likevel erfarte de behandlingen som trygg og av høy kvalitet. Mange trakk frem fordeler ved enerom, et rolig, hjemmekoselig miljø og nærhet til eget hjem. Pasientene opplevde oppholdet som positivt sammenliknet med tidligere sykehusopphold, som ble beskrevet som hektisk, stressende og at personalet der hadde lite tid. En studie av 189 pasienter utskrevet fra en avdeling for generell indremedisin/geriatri på sykehus som ble gjennomført parallelt med studien over, viste at en større andel pasienter rapporterte om problemer etter innleggelse på sykehus enn etter innleggelse på kommunale akutte døgnenheter (11).

\section{Pasientens helsetjeneste}

Vi har i Norge flere eksempler på lokale døgntilbud i skjæringspunktet mellom spesialisthelsetjeneste og kommunehelsetjeneste. Delvis har disse vært en del av en lang tradisjon, som sykestuene i Finnmark, og delvis av nyere dato, som de kommunale akutte døgnenhetene. Både benevnelser, organisering og funksjoner varierer, men felles for dem er at tilbudet er rettet mot deler av pasientforløpet der behovet for tjenester befinner seg i en gråsone mellom hva som kan tilbys ved sykehus og i kommunen. Alle tilbudene krever uansett god kompetanse hos helsepersonellet.

Våre studier har vist at lokale enheter kan tilby sikre tjenester med god kvalitet, og at pasientene fremhever det lokale, hjemlige alternativet fremfor behandling ved større sykehus. Dette støttes av internasjonale studier som viser at pasienter foretrekker å bli behandlet i mindre hektiske, lokale enheter (12).

Kunnskapssenteret oppsummerte i 2014 resultater fra studier nasjonalt og internasjonalt der man sammenlignet effekter av å legge inn pasienter i en lokal forsterket døgnenhet med innleggelse av samme type pasienter i sykehus. Kun tre studier oppfylte inklusjonskriteriene. Resultatene viste at innleggelse i lokal akutt døgnenhet sammenlignet med innleggelse i sykehus kan gi bedre pasienttilfredshet, men det var ikke mulig å avgjøre om slike innleggelser påvirket fysisk funksjon og livskvalitet eller påvirket antall reinnleggelser (13). Det er også vist at det primært er eldre pasienter som legges inn ved de kommunale akutte døgnenheter og at beleggsprosenten er lavere enn forventet (14). Vidt formulerte lovbestemmelser har åpnet for ulike løsninger og tilpasninger i kommunene. At forskjellene mellom enhetene er store både nasjonalt og internasjonalt og at det dermed er vanskelig å sammenligne og trekke konklusjoner, har vært noe av diskusjonen omkring både sykestuer, intermediæravdelinger og kommunale akutte døgnenheter.

Tilbud i lokale, mindre enheter kan være et hensiktsmessig alternativ til sykehusinnleggelse. Slike enheter gir avlastning for sykehusene og kan gi positive helsekonsekvenser for pasientene til en lavere kostnad. Tilbudene representerer på denne måten en tjeneste «i stedet for» sykehus, men de tilfører i tillegg en selvstendig kvalitet i tråd med behovene, særlig hos de eldre og de med kroniske sykdommer. Dette innbefatter løsninger med lokale tilbud (nærhet, små, "hjemlige" oversiktlige tilbud uten sykehusets stress), kontinuitet og en holistisk tilnærming. Selvsagt må det tas visse forbehold. Ethvert lokalt tilbud kan ikke uten videre sies å være et likeverdig alternativ til sykehuset. Det må foreligge en riktig utvalgt pasientgruppe, et forsvarlig medisinskfaglig nivå og en systematisert observasjonskompetanse ved behandlingstilbudet (9).

Det er en utfordring at man i Norge lar "de tusen blomster blomstre". Det er ingen enhetlig tenkning rundt de intermediære tilbudene. Disse representerer alt fra en halv sengeplass på et sykehjem til 116 senger ved Øya Helsehus i Trondheim. De har ulik organisering, ulike eiere og finansiering, og de har ulike faglige tilbud og ulike faglige krav. I møte med det stigende antall eldre og et $\varnothing \mathrm{kt}$ antall pasienter med kroniske lidelser vil ikke sykehusene, slik vi kjenner de i dag med stadig økte krav til effektivitet og spesialisering, kunne gi et tilfredsstillende tilbud til disse pasientgruppene. For å kunne møte fremtiden med et 
bærekraftig helsevesen, trenger vi en nasjonal utredning der man undersøker tilbud i skjæringspunktet mellom spesialisthelsetjeneste og kommunehelsetjeneste. Denne bør danne grunnlag for en ny nasjonal helseplan. Det er behov for å avklare både ansvarsforhold og hvordan disse tilbudene skal se ut. Helseplanen bør ta utgangspunkt i «pasientens helsetjeneste», der krav om effektivisering bør være underordnet pasientens behov.

\section{LITTERATUR:}

1. Magnussen J, Hagen TP, Kaarboe OM. Centralized or decentralized? A case study of Norwegian hospital reform. Soc Sci Med 2007; 64: 2129 - 37. [PubMed][CrossRef]

2. NOU 2005:3. Fra stykkevis til helt - en sammenhengende helsetjeneste. https://www.regjeringen.no/no/dokumenter/nou-2005-03/id152579/(8.6.2017).

3. Forskningsrådet. Evaluering av samhandlingsreformen. Sluttrapport fra styringsgruppen for forskningsbasert følgeevaluering av samhandlingsreformen (EVASAM). Lysaker: Norges forskningsråd, 2016.

4. Swanson JO, Hagen TP. Reinventing the community hospital: a retrospective population-based cohort study of a natural experiment using register data. BMJ Open 2016; 6: eo12892.

[PubMed][CrossRef]

5. Wessel A. Hygiene, social medicin, lægeforhold mv. Bidrag til Finnmark fylkes medicinalhistorie. Tidsskr Nor Legeforen 1929; 49: 992 - 1006.

6. Aaraas I. General practitioner hospitals: Use and usefulness. ISM skriftserie nr. 45. Tromsø: Institutt for samfunnsmedisin, 1998.

7. Garåsen H, Magnussen J, Windspoll R et al. Eldre pasienter i sykehus eller i intermediaeravdeling i sykehjem - en kostnadsanalyse. Tidsskr Nor Laegeforen 2008; 128: 283 - 5. [PubMed]

8. Garåsen H. The Trondheim Model. Improving the professional communication between various levels of health care services and implementation of intermediate care at a community hospital provide better care for older patients. Doktorgradsavhandling. Trondheim: Norges teknisknaturvitenskapelige universitet, 2008.

9. Lappegard $\emptyset$. Acute admission at Hallingdal sjukestugu. Can and should local medical centres play a role in Norwegian healthcare services for acute admissions of a specified group of patients? Doktorgradsavhandling. Oslo: Universitetet i Oslo, 2016.

10. Leonardsen A. Experiences with decentralized acute healthcare services from different stakeholders' perpsectives. A mixed methods study. Doktorgradsavhandling. Oslo: Universitetet i Oslo, 2017.

11. Leonardsen AL, Jelsness-Jørgensen LP. Patient experiences and predictors in an acute geriatric ward: A cross-sectional study. J Clin Nurs 2017. [PubMed][CrossRef]

12. Small N, Green J, Spink J et al. The patient experience of community hospital - the process of care as a determinant of satisfaction. J Eval Clin Pract 2007; 13: 95-101. [PubMed][CrossRef]

13. Forsetlund L, Holte HH. GH S. Lokale akutte døgntilbud sammenlignet med innleggelse i sykehus. Rapport nr. 24. Oslo: Kunnskapssenteret, 2014.

14. Skinner M. Øyeblikkelig hjelp døgnopphold. Oppsummering av kunnskap og erfaringer fra de første fire årene med kommunalt øyeblikkelig hjelp døgnopphold. Gjøvik: Høgskolen i Gjøvik, 2015.

Publisert: 4. september 2017. Tidsskr Nor Legeforen. DOI: 10.4045/tidsskr.17.0324

Mottatt 2.4.2017, første revisjon innsendt 18.5.2017, godkjent 8.6.2017.

(C) Tidsskrift for Den norske legeforening 2020. Lastet ned fra tidsskriftet.no 